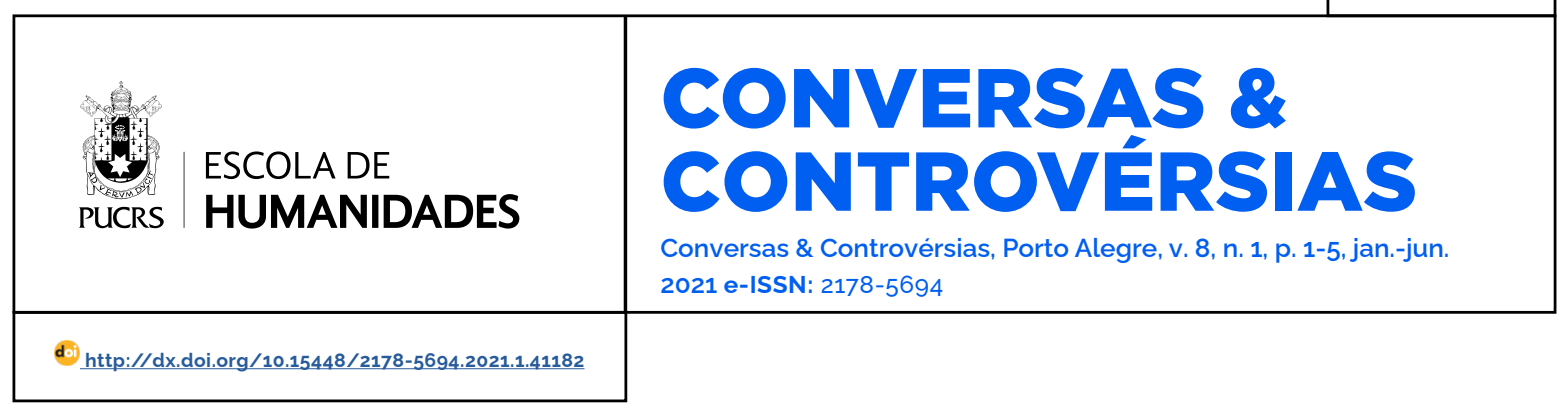

SEÇÃO: RESENHA

\title{
Tecnodiversidade, de Yuk Hui
}

Technodiversity, by Yuk Hui

\section{Gabriela Berghahn \\ Santana ${ }^{1}$ \\ orcid.org/0000-0001-8680-017X gabrielaberghahn@hotmail.com}

\section{Marthina Borghetti \\ Rosa da Silveira ${ }^{1}$}

orcid.org/0000-0002-0257-8135

marthiborg@gmail.com

Recebido em: 24 jun. 2021

Aprovado em: 24 jun. 2021.

Publicado em: 23 ago. 2021.
Resumo: A presente resenha tem como objetivo apresentar o novo livro de Yuk Hui, Tecnodiversidade. Nessa obra, o filósofo da tecnologia defende o desenvolvimento de um novo pensamento reflexivo, em torno da tecnologia a partir da localidade. A tecnodiversidade é pensada como o caminho para a construção de uma nova era, que daria fim à globalização unilateral e ao avanço tecnológico dependente do europeu, consequências do paradigma iluminista.

Palavras-chave: Tecnodiversidade. Tecnologia. Arte. Filosofia.

Abstract: The main goal of the following review is to present Yuk Hui's new book: Technodiversity. In this work, the philosopher of technology defends the development of a new reflective way of thinking about technology from locality. The technodiversity is formulated as the path for constructing a new age, ending unilateral globalization and the technological progress dependent of the European, consequences of Enlightenment's paradigm.

Keywords: Technodiversity. Technology. Art. Philosophy.

Yuk Hui é pesquisador e professor da Universidade de Hong Kong e professor visitante da Pós-Graduação em Filosofia e Tecnologia na Academia de Artes da China, em Hancheu. Também é fundador da Research Network for Philosophy and Technology, plataforma internacional que facilita a pesquisa sobre arte e tecnologia.

Em seu mais recente livro, Tecnodiversidade, publicado em 2020, Hui apresenta um conjunto de ensaios nos quais formula suas investigações acerca das relações entre a humanidade e a tecnologia na contemporaneidade, estereótipos, senso-comuns e também as ligações com os campos social e político, passando pelos temas ecologia, arte, inteligência e inteligência artificial. $O$ autor reflete a respeito do avanço tecnológico unilateral e suas consequências no atual cenário político, sobre a crise da democracia e como ela influencia as formas de usar e pensar a tecnologia.

O filósofo da tecnologia propõe uma rearticulação da questão das relações entre tecnologia e sociedade, colocando-se contra a interposição da tecnologia entre a humanidade e o cosmos, a favor da redescoberta

\section{(c) (i)}

Artigo está licenciado sob forma de uma licença Creative Commons Atribuição 4.0 Internacional. 
da multiplicidade de cosmotécnicas, bem como da reconstrução de suas histórias particulares. O conceito de "cosmotécnicas" refere-se a tecnologias desenvolvidas em contextos locais, pertencendo e definindo certo cosmos cultural, cuja retomada permitiria pensar uma filosofia da nova era, em conjunto e pela diversidade técnica, tecnológica, política e cultural.

Para isso, Hui sugere uma reabertura da história mundial, pautada nos diálogos transversais entre culturas, para reposicionar a tecnologia enquanto sujeito de investigação e de transformação, na perspectiva de múltiplas cosmotécnicas. Pois, "podemos suspeitar que tem havido um engano e um desconhecimento quanto à tecnologia nos últimos séculos, já que ela tem sido vista como algo não essencial e de caráter meramente instrumental - mas, de modo mais significativo, como homogênea e universal" (Hui 2020, 17).

Assim, a reflexão sobre outros futuros possiveis, que é um imperativo na atualidade, deve passar pela questão da tecnologia, redescobrindo as histórias das diferentes cosmotécnicas, em contraposição com os discursos da modernidade e da globalização, pautados na história linear europeia, pois, "sem confrontarmos o conceito de tecnologia em si, dificilmente seremos capazes de preservar a alteridade e a diferença" (Hui 2020, 19).

No primeiro capítulo, escrito originalmente em 2017. Hui propõe seu conceito de cosmotécnica articulado à cosmopolítica, uma nova geopolítica, que não se restringe apenas a uma mudança de hegemonia, mas ao fim da globalização unilateral. Essa última, universaliza epistemologias particulares em nome de uma hegemonia cultural vendida como global, apagando suas origens locais e as demais epistemologias.

Nesse sentido, o conceito de cosmopolítica é reativado a partir da definição kantiana de cosmopolita, como uma política da natureza, mas também como um futuro regime comercial global da diversidade política e técnica. A política da natureza é pensada, aqui, para além da dualidade natureza/cultura, afirmando a historicidade dessa divisão. Hui ressalta que a colonização que levou à globalização unilateral foi técnica e tecnológica e, dessa forma, as cosmologias europeias espalharam-se pelo globo e, com elas, propaga-se, também, essa visão dual, muito característica da modernidade europeia. O conceito de cosmopolítica busca, então, a reconciliação do particular com o universal, não em termos de hegemonia, mas em termos de alteridade e relação.

A consciência da multiplicidade de cosmotécnicas (tecnodiversidade) é a forma de repensar a geopolítica na crise do Antropoceno, pois afirma o caráter local das tecnologias, limitadas e movimentadas por cosmologias particulares. O reconhecimento dessa multiplicidade é uma ferramenta política para pensar além dos paradigmas binaristas modernos europeus e da globalização unilateral, que resulta em hegemonia universalizante, "uma forma de neocolonização, que impõe sua racionalidade via instrumentalidade" (Hui 2020, 41).

Nos segundo e terceiro capítulos, Sobre a Consciência Infeliz dos Neorreacinários e O que vem Depois do Fim do Iluminismo, escritos originalmente em 2017 e 2019, o pesquisador examina o pensamento neorreacionário no século XXI, tratando sua emergência como uma consequência da perda de potência do Ocidente e da decadência dos paradigmas iluministas. 0 pensamento reacionário é, aqui, uma forma de ceticismo, que não consegue olhar para fora de si. Nesse sentido, Hui retoma o conceito de "consciência infeliz", de Hegel, uma "confusão de sentimentos histórica" (Hui 2020, 52), certo niilismo com mania de revisionismo. O ódio à democracia é consequência desse conjunto de ideias, pois a democracia, criada no mito do lluminismo, é vista como limitante das liberdades de direito.

Nessa perspectiva, o Iluminismo acaba servindo como um bode expiatório para a confusão conceitual dos autores analisados por Hui, que enxergam, nas políticas social-democratas, raizes iluministas e acreditam no sacrifício da política em nome da produtividade econômica. Consideram a geopolítica atual como uma política improdutiva, marcada pelo politicamente correto, derivada da propagação dos ideais iluministas.

O filósofo comenta que "os limites à globalização [unilateral] não foram traçados pela mentira ilumi- 
nista, como os neorreacionários afirmam, mas são apenas a manifestação de um zeitgeist no qual a colonização, a industrialização e o nascimento da economia se sobrepõem" (Hui 2020, 64). Esse levante é derivado, então, de certa "ansiedade quanto ao ocidente ser incapaz de superar a atual fase da globalização e de manter os privilégios desfrutados ao longo das últimas centenas de anos" (Hui 2020 , 65). Porque "somente a partir de uma intervenção tecnológica invasiva que o ocidente poderá se recuperar da democracia" (Hui 2020, 70).

Para revidar os ataques, o autor novamente propõe pensar a partir do resgate das cosmotécnicas não-ocidentais e de suas histórias particulares, desmontando a sincronização da história, que só entende a linha evolutiva do "progresso". Desmontar a sincronização dessa ciência e dos currículos escolares, resgatar epistemologias e desenvolver novas epistemes são os caminhos que buscam "fragmentar o mundo de acordo com o diferente, em vez de universalizá-lo através do mesmo; introduzir o mesmo através do diferente, em vez de deduzir o diferente a partir do mesmo" (Hui 2020, 72).

A partir disso, Hui desenvolve, novamente, algumas ideias neorreacionárias, destrinchando-as. Uma delas é a de que a aceleração tecnológica contemporânea corresponde ao fracasso dos ideais iluministas, que culmina em um sentimento de triunfalismo pós-humanista, advindo da Inteligência Artificial, que é expandida como um meio de hegemonia quase eugenista do ocidentalismo.

A crítica do filósofo a esse ponto tem a ver com os processos de desterritorialização, provocados pelo capitalismo global em sua fase atual. O pesquisador comenta sobre as atualizações, deslocamentos e adaptações promovidos pelo sistema capitalista, em nome da manutenção de suas lógicas intrínsecas, e ressalta o papel da tecnologia nesses processos. Então, para o autor, é preciso rejeitar o discurso unificador do humano, ligado a um processo de modernização como forma de sincronização. Para isso, faz-se necessário bifurcar sucessivamente o eixo da história, dando à tecnologia um novo referencial, que se adeque à multiplicidade de cosmotécnicas.

É importante lembrar que Hui coloca, ainda, que a necessidade da tecnodiversidade também impõe a necessidade de múltiplas cosmoéticas, inseridas em um futuro de globalização multicultural e verdadeiramente democráticas. Assim, retoma a questão de repensar o processo da modernidade, de forma a conseguirmos imaginar outros futuros, revisitando a história da racionalidade e de suas relações com a natureza e a tecnologia, dessa vez objetivando buscar e manter a tecnodiversidade.

Nessa perspectiva, Yuk Hui reflete sobre a ecologia das máquinas, no quarto capítulo do livro, Máquina e Ecologia, escrito originalmente em 2019. O conceito de tecnodiversidade é fundamental para aprofundar a reflexão sobre as relações entre máquina, ecologia e a historicidade dessas categorias, refletindo a partir dos limites do ambiente, da cultura e do pensamento geográfico. O pesquisador não defende que a tecnologia deve atravessar dilemas morais em nome do progresso, ignorando, dessa forma, os desastres naturais e desigualdade social e tomando-os como inevitáveis para o avanço tecnológico e econômico.Também, não defende que devemos evitar a inteligência artificial a qualquer custo. Ao invés disso, traz uma forma de pensarmos para além do que já está dito sobre o futuro e criarmos caminhos a partir da reflexão sobre as tecnologias.

Hui propõe que a recursividade do feedback, presente na ecologia e nas máquinas, é uma visão possivel de como superar a binaridade da Europa moderna. A recursividade é importante, por ser característica da operação não linear que retorna constantemente para si, a fim de se conhecer e se determinar. Desde McLuhan, a palavra "ecologia" perdeu seu caráter estritamente biológico, de modo que analisar as relações complexas e não lineares pela dualidade sincrônica não faz mais sentido. Devendo, portanto, ser analisadas como um complexo tecnologia-ambiente. O capital é, agora, um modelo organicista, levado a cabo por máquinas informacionais equipadas com algoritmos recursivos complexos. Assim, para compreendermos as pautas sociais, ambientais e tecnológicas contemporâneas, é necessário abrirmos espaço para uma nova forma de entendimento do que 
é inteligência, que possa incluir a recursividade, o sensorial e a arte.

É no capítulo Variedades da Experiência da Arte, desenvolvido a partir de três palestras, que aconteceram em 2019, durante a aula magna What Art Can Do in the 21st Century (O que a arte pode fazer no século 21?), na Universidade Nacional de Artes de Taipei, que o autor disserta sobre as relações possiveis entre arte e tecnologia. Para Hui, a arte possui a capacidade de unir o pensamento científico ao filosófico. Para desenvolver novos pensamentos filosóficos, estéticos e tecnológicos, que deem fim à cibernética e ao pensamento europeu moderno como sinônimo de desenvolvimento, é necessária a fragmentação e a dessincronização. A filosofia pós-europeia, pensada a partir de todos os continentes, pode ser alcançada por meio dessa fragmentação. É nesse momento que a arte se encaixa, pois teria, em sua essência, a localidade, bem como o pensamento recursivo e não linear.

A arte é, para Hui, um meio de acesso ao não racional, o tao ocidental, com sua capacidade de explorar o sensorial e educar sobre a sensibilidade. a partir dos múltiplos entendimentos de inteligência e experiência. Para o autor, o não racional é importante para pensarmos as cosmotécnicas, visto que:

O sentido concreto do não racional se correlaciona com o mundo cosmológico em que as pessoas vivem e que molda a mentalidade das culturas; seus meios de acesso são expressos pela arte e pelas tradições, uma experiência estética que se mostra excepcional e extra- ordinária no sentido de que racionaliza o não racional e constrói um plano de uniformidade no que concerne a uma vida espiritual. (Hui 2020, 143).

É na arte que os pensamentos cientíico - voltado ao aprimoramento de técnicas e tecnologias - e filosófico - voltado ao desenvolvimento de novos sentidos - podem ser explorados em conjunto.

Para a criação de uma nova filosofia não europeia também é necessária a evolução da inteligência artificial. No capítulo Sobre os Limites da Inteligência Artificial, descrito originalmente também em 2019, Hui disserta sobre tal evolução, trazendo o seguinte questionamento:

\begin{abstract}
A transformação do humano levará à extinção do Homo sapiens? Ou essa transformação nos conduzirá a uma abertura - uma abertura que não apenas rejeite o humanismo, mas que também rearticule as questões da história, da cultura e da vida? (Hui 2020, 175).
\end{abstract}

Porém, a inteligência artificial não está apenas restrita ao desenvolvimento de uma superinteligência, já que o próprio conceito de inteligência não pode ser limitado pelo uso de cálculos e análise de fenômenos. Deve-se considerar os aspectos não racionais e simbólicos, que envolvem a moral e a cultura. Isso não significa estudar apenas sobre a ética da tecnologia, mas voltar aos modos de conhecimentos diferentes, que ainda não foram considerados por cientistas e engenheiros.

Yuk Hui finaliza o livro com seu ensaio mais recente, Cem Anos de Crise, no qual discorre sobre a atual pandemia de coronavírus e a dificuldade dos paises em contê-la. Seja pela demora da Organização Mundial da Saúde em organizar um plano de controle do vírus ou pela volta instintiva às fronteiras dos Estados-Nação, que têm sido borradas pelo capitalismo global e o World Wide Web. Para o autor, a forma com que estamos lidando com a pandemia é resultado de uma cultura monotecnológica, e com ela muitas instituições deixarão de existir, por conta dos avanços digitais. Para conter a propagação do vírus, serão necessárias atitudes empáticas de todos os países, agir como um globo, sem deixar de lado as diferenças locais, o que o autor chama de solidariedade concreta.

Essa reflexão, e todas as outras que o autor traz em seu livro, mostram-se importantes, tendo em vista as mudanças que a tecnologia causa nos múltiplos âmbitos da sociedade. Essa necessidade aumenta a partir da pandemia, que isola as pessoas e as confina cada vez mais nos limites dos seus respectivos domicilios. Assim, a internet, e com ela as plataformas de comunicação e as redes sociais, torna-se necessária para trabalho, estudo e lazer.

Neste momento, o biológico e o político são um só, mas o retorno desesperado às fronteiras do Estado-Nação impede que a crise seja entendida como o que ela realmente é, ou seja, global. Essa lógica é uma barreira à coimunização global, pois 
segue os principios da soberania e da dualidade amigo-inimigo. No entanto, é nítido que essas fronteiras já não têm o mesmo propósito e impacto que tinham anteriormente. Em tempos de multinacionais e World Wide Web, de governos eleitos por fake news criadas por empresas de outros países, a guerra contra o vírus é, também, uma guerra da informação.

Portanto, é necessária, para a coimunização massiva e global, a solidariedade concreta. E essas redes de solidariedade concreta podem ser as mesmas que construirão infosferas diversas, superando a guerra informacional, em um resgate da tecnodiversidade, bem como de seus diversos modos de acesso, colaboração e epistemologia, em oposição à cultura monotecnológica da globalização unilateral e dependente. É necessário, por fim, buscar uma nova agenda e imaginação tecnológicas, que possibilitem novas formas de vida social, política e estética, para, assim, lidarmos com a crise do Antropoceno e imaginarmos futuros possiveis e democráticos.

\section{Referências}

Hui, Yuk. 2020. Tecnodiversidade. São Paulo: Ubu Editora.

\section{Gabriela Berghahn Santana}

Graduanda em Artes Visuais - Bacharelado, pela Universidade Federal do Rio Grande do Sul, em Porto Alegre, RS, Brasil. Atua como bolsista de Iniciação Científica (BIC-UFRGS) na pesquisa "Produção e Veiculação da Arte na Internet: Plataforma Verter" desde 2020.

\section{Marthina Borghetti Rosa da Silveira}

Graduanda em Artes Visuais pela Universidade Federal do Rio Grande do Sul (UFRGS), em Porto Alegre, RS, Brasil. Trabalha com Ensino de Arte e ilustração. Suas pesquisas giram em torno das relações entre arte e sociedade na contemporaneidade. 